\title{
Recovery of Inter-Row Shading Losses Using Differential Power-Processing Submodule DC-DC Converters
}

\author{
Kate Doubleday, Beomseok Choi, Dragan Maksimovic \\ University of Colorado, Boulder

\section{Chris Deline} \\ National Renewable Energy Laboratory

\section{Carlos Olalla} \\ Universitat Rovira i Virgili
}

\begin{abstract}
:
Large commercial photovoltaic (PV) systems can experience regular and predictable energy loss due to both inter-row shading and reduced diffuse irradiance in tightly spaced arrays. This paper investigates the advantages of replacing bypass diodes with submodule-integrated DC-DC converters (subMICs) to mitigate these losses. Yearly simulations of commercial-scale PV systems were conducted considering a range of row-to-row pitches. In the limit case of array spacing (unity ground coverage), subMICs can confer a 7\% increase in annual energy output and peak energy density $\left(\mathrm{kWh} / \mathrm{m}^{2}\right)$. Simulation results are based on efficiency assumptions experimentally confirmed by prototype submodule differential power-processing converters.
\end{abstract}

Keywords: photovoltaic systems, power electronics, partial shading, energy conversion, power system simulation

\section{Introduction}

Mismatches due to partial shading, aging, soiling, temperature gradients, and manufacturing tolerances cause a disproportionately large reduction in energy output in photovoltaic (PV) systems (MacAlpine, 2013; Jordan, 2012). Module-level power electronics, including series-connected DC-DC converters or per-module AC micro-inverters, have been shown to recover $25 \%-35 \%$ of energy lost to shading mismatches; integrating power electronics at a finer granularity within the module has the potential to increase energy recovery further (Deline \& Meydbrey, 2014). Conventional PV modules have bypass diodes across each

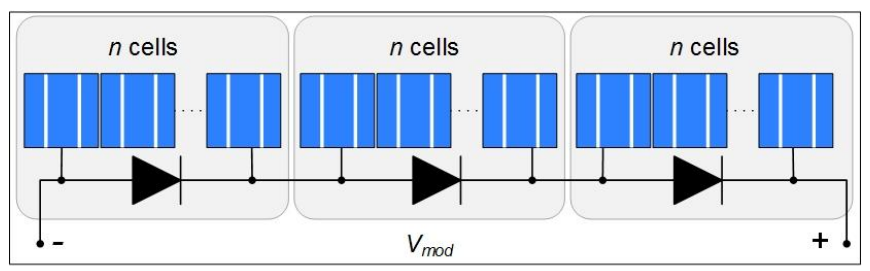

(a)

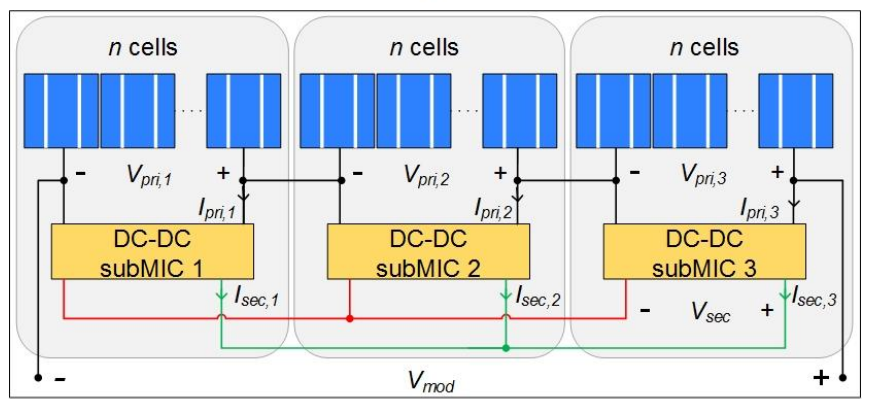

(b)

Figure 1: (a) Conventional module architecture with bypass diodes across each submodule of $n$ cells. (b) Isolated-port submodule-integrated DC-DC converter topology, which only processes the mismatched power between submodules. 
submodule of $n$ cells to bypass mismatched regions (Figure 1(a)). Replacing bypass diodes with submodule-integrated DC-DC converters (subMICs) in parallel with each submodule, as shown in Figure 1(b), can accomplish distributed, fine-granularity maximum-power-point tracking (MPPT) (Olalla, TPEL 2013). In contrast to series-connected DC-DC converters, the parallelconnected subMICs do not add insertion losses, and the system is not vulnerable to open-circuit failures because the subMIC switch body diode effectively preserves the reverse-bias protection of a conventional bypass diode. Furthermore, only the mismatch power is processed differentially, which allows for partial-power-rated subMICs (Olalla, 2014).

As shown in Figure 1(b), subMICs can be implemented as isolated-port bidirectional converters, which allows the secondary-port voltage, $V_{s e c}$, to be independent of the primary-port voltage, $V_{p r i}$. This approach allows for independently operated subMICs, trading MPPT accuracy for simplicity of control (Olalla, TPEL 2013; Olalla, 2015). As has been shown in other prior publications, many other implementations of subMICs can be achieved, including full-power processing subMICs (PilawaPodgurski, 2013), and ladder circuits (Kesarwani, 2012; Shenoy, 2013; Shibin, 2013).

In this paper, the subMIC architecture of Figure 1(b) is applied to PV installations with high ground-coverage ratios (GCRs) that suffer from inter-row shading (Figure 2). This is a new application that has recently been investigated in conference papers (Deline \& Sekulic, 2014; Doubleday, 2015; Galtieri, 2015).

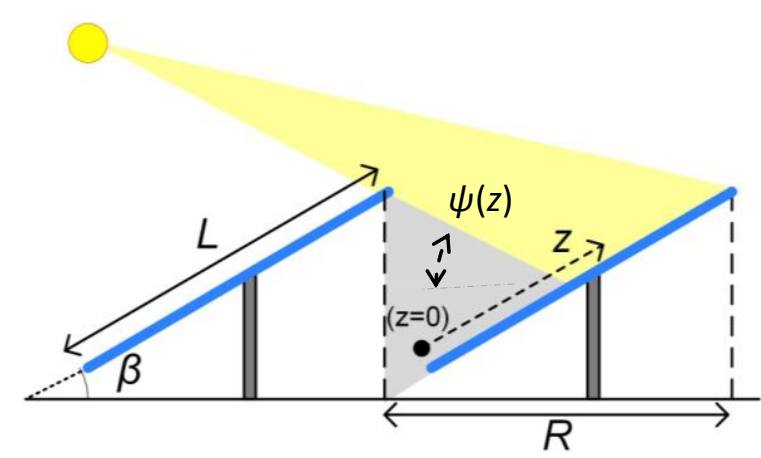

Figure 2: Ground-coverage ratio (GCR) is the ratio of module area to land area, or the ratio of array length to row-to-row pitch $(L / R)$. Inter-row shading increases with GCR. $\beta$ is the tilt angle, and $z$ measures height along the array. The screening angle $\psi(z)$ represents a two-dimensional field-ofview reduction at height $z$.

As shown in Figure 2, GCR is calculated as the ratio of PV module area to total land area, where $L$ is the length of the array and $R$ is the row-to-row pitch:

$$
\mathrm{GCR}=\frac{L}{R} .
$$

An array with short $R$ and high GCR has the advantage of high energy production per land area $\left(\mathrm{kWh} / \mathrm{m}^{2}\right)$, but generates less total energy compared to a similarly rated array with longer row-to-row pitch and less inter-row shading loss (Deline \& Meydbrey, 2014; Deline \& Sekulic, 2014).

Up to about $60 \%$ of beam irradiance lost to inter-row shading is recoverable with power electronics integrated at the level of the bypass diode (Deline \& Meydbrey, 2014). However, diffuse irradiance loss from a reduced view of the sky in tightly spaced arrays was not accounted for, so total energy recovery is likely to be lower (van Schalkwijk, 1997). The current study simulates the actual recovery incorporating cell-level diffuse loss to better gauge the advantages of integrating subMICs in PV installations with high GCRs. 
In addition, we show here an experimental validation of the ability of differential power-processing submodule DC-DC converters to reduce mismatch loss. The subMIC architecture of Figure 1(b) was realized in a prototype circuit, which was then subjected to simulated inter-row shading mismatch conditions. Experimental and simulated results are compared under this partial-shade mismatch condition.

This paper is organized as follows. Section 2 presents the simulation tool and the system scenarios considered. Section 3 describes an experimental subMIC prototype placed in the junction box of a commercial PV module. Section 4 and Section 5 present simulation and experimental results, respectively.

\section{Simulation Setup}

\subsection{Simulation Tool}

A Matlab program was developed to calculate PV array production accounting for partial shading, temperature, and irradiance at the cell level (Olalla, 2014; Olalla COMPEL, 2013). For this simulation, hourly cell-level operating conditions of a PV system are solved using classical numerical methods, with irradiance mismatch defined by the extent of inter-row shade.

The solar cell model is described by the standard five-parameter equation, as in Duffie (2006):

$$
I_{\text {cell }}=f\left(V_{\text {cell }}, I_{\text {cell }}\right)=I_{g_{j k}}-I_{d r s}\left(e^{\frac{V d_{j k}}{a \cdot V_{T}}}-1\right)-\frac{V_{d}}{R_{p}},
$$

where $V_{d_{j k}}=V_{\text {cell }}{ }_{j k}+I_{\text {cell }} \cdot R_{s}, I_{d r s}$ is the diode reverse saturation current, $R_{p}$ and $R_{s}$ are the shunt and series resistances, and $a$ is the diode quality factor. These cell parameters are chosen to represent a standard $250 \mathrm{~W}, 60$-cell PV module. Note that $I_{g_{j k}}$ is the photocurrent at submodule $j$ cell $k$; therefore, cells may have unique maximum power points. Photocurrent $I g_{j k}$ depends linearly on the incident irradiance and the fraction of shaded cell area $\alpha_{j k}$ :

$$
I_{g_{j k}}=\left(G\left(1-\alpha_{j k}\right)+\left(D-D_{l o s s}\right) \cdot \alpha_{j k}\right) \frac{I_{s c}}{G_{0}},
$$

where $G$ and $D$ are incident unshaded global and diffuse irradiance, respectively, and $G_{0}$ is the reference $1000 \mathrm{~W} / \mathrm{m}^{2}$ irradiance under standard test conditions (STC). $D_{\text {loss }}$ is a diffuse-loss term from Eq. (5). In experiments, $G$ and $D$ were measured on-site, along with shading data $\alpha_{j k}$. For simulations, horizontal components $G_{h}$ and $D_{h}$ were obtained from a meteorological database assuming conditions at Sacramento, CA (Measurement and Instrumentation Data Center, 2012), and shading data were obtained by geometry as described below. Temperature effects are calculated according to De Soto (2006).

Three PV system architectures have been simulated in this tool: (1) a conventional central-inverter architecture with bypass diodes across submodules of $n=20$ cells; (2) a module-integrated converter (MIC) architecture assumed to provide module-level DC-DC conversion at 99\% efficiency (e.g., SolarEdge, 2015); and (3) the subMIC architecture of Figure 1(b) deployed across submodules of either $n=20$ cells (three per module) or $n=10$ cells (six per module). Real performance parameters of the subMIC circuit (described in Olalla TPEL, 2013; Levron, 2014; Olalla, 2015) are modeled here, such as 90\% conversion efficiency, imperfect maximum-power-point tracking, and a finite turn-on voltage. Additionally, subMICs are assumed to have a reduced power-processing limit relative to the module's maximum power, to assess the impact of circuit components of reduced size/cost.

\subsection{Row-Shading Calculations}

Plane-of-array components $G$ and $D$ are calculated by Perez transposition of horizontal components (Perez 1990), with cell-level $\alpha_{j k}$ shading values calculated throughout the day according to the geometric method of Appelbaum (1979). 
Diffuse irradiance loss for interior rows is calculated annually by use of a screening angle $\psi(z)$, which corresponds to the angle at which the view of the sky is restricted at a height $z$ along the array, as shown in Figure 2:

$$
\psi(z)=\arctan \left\{\frac{(L-z) \sin \beta}{R-L \cos \beta+z \cos \beta}\right\} .
$$

The plane-of-array diffuse loss $D_{\text {loss }}(\psi)$ is calculated as in Passias (1984), where $D_{h}$ is the horizontal diffuse component of irradiance:

$$
D_{\text {loss }}(\psi)=D_{h}\left\{1-\cos ^{2}\left(\frac{\psi}{2}\right)\right\} .
$$

The diffuse view-factor angle $\psi$ is calculated individually for each cell using the worst-case $z$ at the bottom of the cell. Note that in the unshaded first row of the array, $D_{\text {loss }}=0$ for all $z$.

\subsection{Simulation Scenarios}

The scenarios described here assume multiple rows of PV modules, arranged three-high in landscape orientation with fifteen horizontally wired modules per row and a fixed tilt of $\beta=20^{\circ}$, south facing. A sensitivity study on the effect of multiple $\beta$ angles was not undertaken; $\beta=20^{\circ}$ was chosen as a representative value. The spacing of the array is adjusted from GCR $=0.62-0.99$ while the number of modules is either kept constant (fixed array-size scenario), or increased as additional modules can be packed into the same $5000 \mathrm{~m}^{2}$ land area (fixed land-area scenario). Note that mounting modules in landscape orientation is important: portrait-oriented conventional modules experience disproportionate losses from inter-row shade (Deline \& Sekulic, 2014) and are therefore considered an unfair comparison.

For the first scenario, the array has a constant 50 rows for a total of 150 parallel strings and a $564 \mathrm{~kW}$ DC power rating. For the fixed $5000 \mathrm{~m}^{2}$ area scenario, the number of rows ranges from 42 to 67 as row packing increases, corresponding to a $473 \mathrm{~kW}-$ $755 \mathrm{~kW}$ DC system power rating.

Annual DC production $E$ is simulated for each row spacing, assuming either conventional central-inverter architecture, or inclusion of power electronics (MICs or subMICs). The ability of alternative architectures to recover inter-row shading loss is represented by the loss-recovery percentage, calculated as:

$$
\% \text { loss recovery }=\frac{E_{M I C}-E_{\text {conventional }}}{E_{\text {unshaded }}-E_{\text {conventional }}} \times 100 \%,
$$

where $E_{\text {unshaded }}$ is the system production of the conventional architecture assuming no shade losses. $E_{\text {Conventional }}$ is the system energy production of the conventional architecture with shade losses, and $E_{M I C}$ is the shaded energy production using the MIC or subMIC architecture.

\section{Experimental Implementation}

A prototype circuit was developed to demonstrate the performance of a subMIC-enhanced PV module under inter-row shading scenarios. Following the isolated-port subMIC architecture of Figure 1(b), three differential power-processing subMICs are integrated on a circuit board and placed in the junction box of a Conergy 175 PV module (Figure 3). These subMICs are $30 \mathrm{~W}-$ rated flyback DC-DC converters similar to those in Levron (2014) and Olalla (2015), but including planar magnetics leading to improved power density (Choi, 2015). 
Overall circuit dimensions are $11.1 \mathrm{~cm} \times 7.3 \mathrm{~cm} \times 1.4 \mathrm{~cm}$, with a volume of $113 \mathrm{~cm}^{3}$. The input-output efficiency of the flyback circuit shows a flat efficiency characteristic around $90 \%$ (Figure 4), even at relatively low power levels. Field exposure of the subMIC-enhanced module was conducted outdoors under full sun $\left(1,000 \mathrm{~W} / \mathrm{m}^{2}\right)$. An approximation of inter-row shading conditions is performed by applying tinted plastic sheets onto one-third of the PV module cells (one submodule). Two levels of tint opacity are tested, equivalent to 5\% (light-shade) or 30\% (medium-shade) shading. Experiment results are presented in Section 5.

Figure 3: Prototype subMIC circuit comprising three separate differential power-processing channels, integrated within a commercial PV junction box. External diagnostic cabling is shown, but not required for circuit functionality.

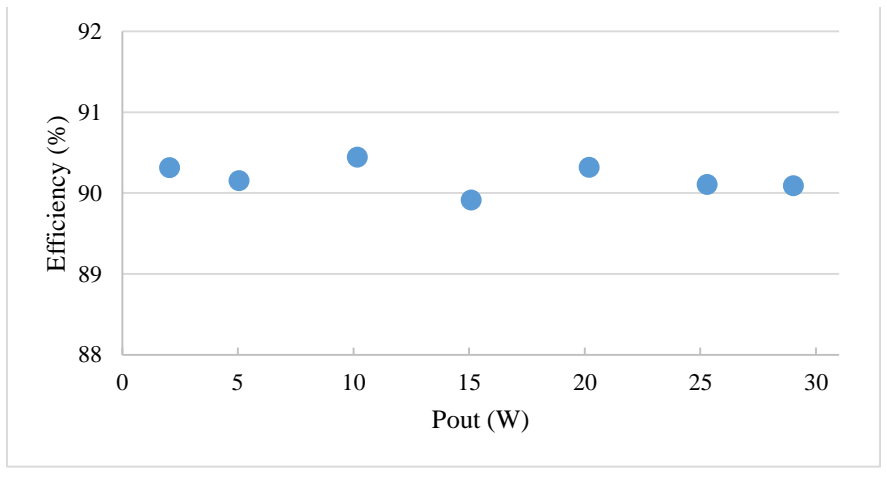

Figure 4: Input-to-output DC conversion efficiency measured for the subMIC flyback circuit is consistently around $90 \%$.

\section{Simulation Results}

\subsection{Fixed Array-Size Scenario}

The first simulation scenario investigates the effect of reduced row spacing on a 564-kW commercial PV system. Annual DC energy output is substantially reduced at higher GCRs as inter-row shading and diffuse irradiance loss become more prominent (Figure 5). In all cases, subMIC-enhanced modules outperform conventional modules at the same row spacing by recovering roughly one-third of the total power loss due to shade. Alternatively, the subMICs allow for a greater GCR (tighter row spacing) for a given energy production. Incorporating subMICs at either granularity allow land-area reductions of 5\%-8\% for a given energy output, compared with the conventional system. 
Deploying six subMICs per module allows for only a modest energy improvement over the case of three subMICs per module. Consequently, our remaining scenarios consider subMICs only at the three-per-module granularity.

Interestingly, the incorporation of module-level DC-DC converters (MICs) does not provide a substantial improvement over the conventional central inverter for this application, because MICs cannot mitigate the effects of mismatch between submodules within a single module. Also, even though the effects of different climate were not studied here, it is expected that conditions tending to increase the diffuse irradiance fraction for a given site would lower the performance advantage of subMICs (Deline \& Meydbrey, 2014).

Figure 5: Simulated annual DC energy output vs. groundcoverage ratio (GCR) for conventional PV modules and modules with integrated subMICs (three or six per module). Module-level DC-DC converters (MIC) provide no improvement under interrow shade.

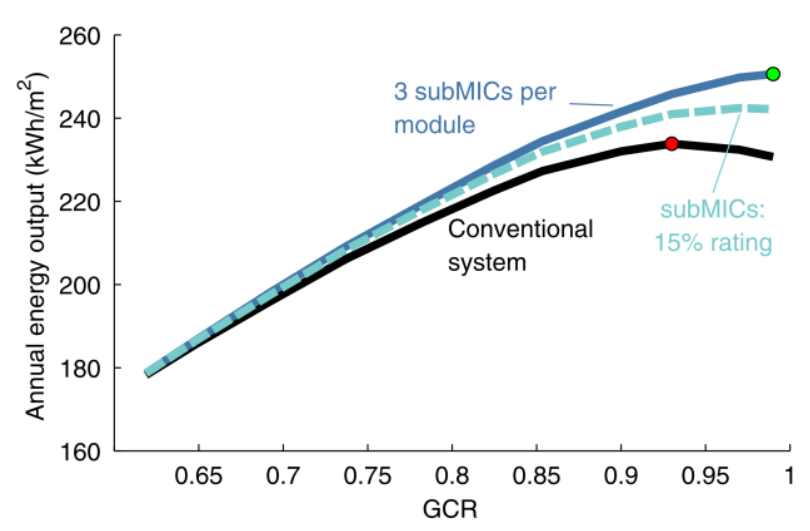

Figure 6: Annual energy output per unit area illustrates the benefits of subMICs at high GCRs. The solid dots indicate maximum energy production from three subMICs per module at $\mathrm{GCR}=0.99$ and from the conventional array at GCR $=$ 0.93 . Also shown for comparison are subMICs rated at $15 \%$ power conversion capability.

A quick economic assessment of subMICs in a high-GCR scenario was conducted. Given a system GCR $=0.8$ and expected total project cost of $\$ 2.5 / \mathrm{W}$ (Feldman, 2014), the extra lifetime electricity produced under the subMIC architecture is calculated at 6.5 $\notin / \mathrm{W}$. Compared with an estimated cost of less than $3 \phi / \mathrm{W}$ for the subMIC circuits (Choi, 2015), subMICs would be economic in this tightly spaced scenario. 


\subsection{Fixed Land-Area Scenario}

The second simulation scenario investigates the effect of maintaining the same land area $\left(5000 \mathrm{~m}^{2}\right)$ and increasing the PV system size from $473 \mathrm{~kW}$ DC to $755 \mathrm{~kW}$ DC as additional rows are added to the system. SubMICs are most beneficial when land is a major constraint, and relative to the conventional PV case, subMIC-equipped modules were found to consistently provide higher annual energy production per $\mathrm{m}^{2}$ (Figure 6). The peak energy density from the conventional array was found to be $234 \mathrm{kWh} / \mathrm{m}^{2}$ at GCR $=0.93$; beyond this point, additional modules provide more shade loss than energy benefit. Here, too, module-level converters (MIC) provide no improvement over the conventional architecture.

For subMIC-equipped modules (three per module), additional module rows always outweigh the additional inter-row shade losses. The peak energy density for subMIC modules $\left(251 \mathrm{kWh} / \mathrm{m}^{2}\right)$ is $7 \%$ higher than the peak energy density of the conventional case $\left(234 \mathrm{kWh} / \mathrm{m}^{2}\right)$. Note that this analysis does not account for the economics of additional modules and components; it is likely that the marginal production of such heavily shaded modules would not be economic, even in an extremely space-constrained application. An additional approach to increasing energy density is to lower the tilt angle of PV modules, reducing inter-row shade. At zero tilt angle, high energy density is possible from conventional systems $\left(265 \mathrm{kWh} / \mathrm{m}^{2}\right)$, but soiling would be a significant practical problem (Mejia, 2013).

Much of the increased production of the subMICs can be achieved with devices rated to only a fraction of the maximum submodule power. SubMICs are connected in parallel with the PV cells and only process a fraction of the power flowing through the PV system; therefore, reduced component rating could also reduce the unit cost and size of the subMIC circuit. For reference, Figure 6 includes subMIC results rated at 15\% of the submodule's STC rating, showing that even at this low power rating, more than half of the production benefit is retained.

Figure 7 shows a histogram of the power processed by each subMIC for the GCR $=0.99$ annual simulation. As expected, subMICs in the bottom module are the most active, whereas those in the top module have very infrequent shading. No subMIC processes any more than $48 \%$ of the maximum submodule power rating over the course of the year. Therefore, there would be potential to reduce the power-processing capability of subMIC components below $50 \%$.

As expected, a reduction in power-processing capability reduces the relative benefit of the subMICs over the conventional case. Figure 8 compares the energy output at GCR $=0.99$ as the subMIC power limit is reduced. As expected, when the power limit approaches zero, subMICs provide no increase over the conventional case.

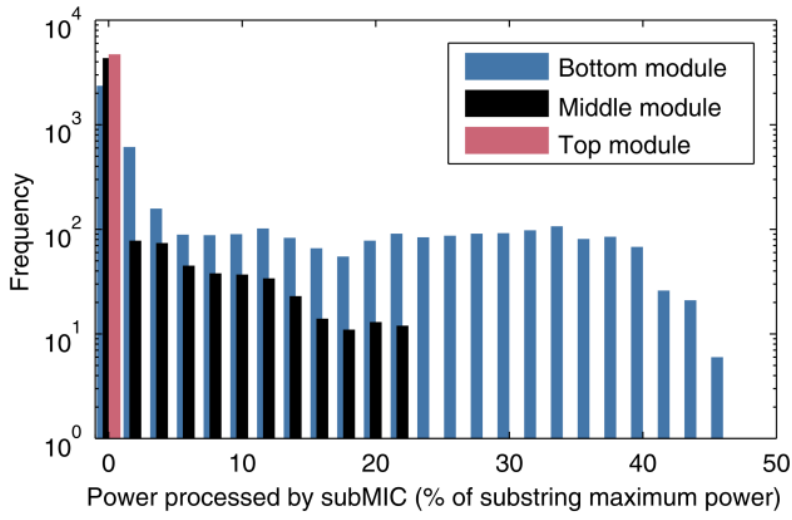

Figure 7: Histogram of power processed by the subMICs in the bottom, middle, and top modules in each row as a percent of the submodule maximum power. 


\section{Experimental Results}

As discussed in Section 3, a prototype subMIC circuit is integrated into a $175 \mathrm{~W}$ PV module junction box and exposed outdoors at a constant $1000 \mathrm{~W} / \mathrm{m}^{2}$ irradiance. The module is allowed to reach steady-state temperature, and DC maximum power is measured with a DC electronic load, both with and without enabled subMICs. With the circuit disabled and under unshaded conditions, $155.2 \mathrm{~W} P_{m p}$ is extracted from the module. With the application of light and medium shade on one submodule, $P_{m p}$ is reduced to $150.9 \mathrm{~W}$ and $122.6 \mathrm{~W}$, respectively. For the subMIC-enhanced module, the extracted power for the cases of no shade, light shade, and medium shade are $155.7 \mathrm{~W}, 152.3 \mathrm{~W}$, and $138.3 \mathrm{~W}$, respectively. The module characteristics near the $P_{m p}$ point are shown in Figure 9. Compared to the standard PV module without subMICs, the output power is increased by $0.3 \%$ (no shade), $0.9 \%$ (light shade), and $11.3 \%$ (medium shade), respectively.

Table I lists these results as production relative to the unshaded performance of the conventional module. Also listed is the performance for a theoretical ideal device where system losses are due only to the presence of shade on one submodule (one third of the module) with no conversion loss.

For the unshaded case, a PV production increase of $0.3 \%$ was measured through the use of subMICs. This increase is near our measurement uncertainty, but may partly reflect a reduction in inherent mismatch within the PV module - it is difficult to be certain. What is more clear is that under shaded conditions, the subMIC performance is similar to that of an ideal device, with conversion power loss on the order of $1 \%$ or less. Considering an input-output conversion efficiency of the subMIC circuit around $90 \%$ (Figure 4), this can be explained by the parallel nature of the subMIC circuit; only a portion of the total power flowing in the PV module is converted by the subMIC circuit. As more PV irradiance mismatch is present at higher shade opacity, more power is processed by the subMIC circuit, and overall conversion losses increase. The experimental results are in line with efficiency assumptions employed in the simulations.

TABLE I

EXPerimental APPlication of Partial Shade, Performance Relative to Unshaded

Relative Performance $\quad$ Clear $(\%) \quad 5 \%$ shade $(\%) \quad 30 \%$ shade $(\%)$

\begin{tabular}{lccc}
\hline \hline $\begin{array}{l}\text { Conventional module } \\
\begin{array}{l}\text { SubMIC-enhanced } \\
\text { module }\end{array}\end{array}$ & 100 & 97 & 79 \\
$\begin{array}{l}\text { Ideal shade recovery } \\
\text { d }\end{array}$ & 100.3 & 98.3 & 89
\end{tabular}




\section{Conclusions}

PV arrays with high ground-coverage ratios suffer energy losses due to inter-row shading and reduced diffuse irradiance. This paper finds that submodule-integrated converters can uniquely address this problem, because module-level devices will not improve performance under inter-row shading conditions. Cell-level simulations indicate that modules equipped with either three or six subMICs achieve similar mismatch-mitigation performances and that a reduced power rating of $50 \%$ still receives the maximum possible benefits of this architecture. An annual energy increase up to 7\% compared to a conventional PV system was found at high GCRs, and the economics of the circuit was calculated to be favorable.

The subMIC simulation model has been validated in part by experimental results. The subMIC circuit was prototyped and integrated in the junction box of a PV module. Under $1000 \mathrm{~W} / \mathrm{m}^{2}$ irradiance and $30 \%$ opaque shading on one-third of the module, we measured a power increase of $11.3 \%$ relative to the conventional PV case. Conversion power loss remained low due to the partial-power-processing nature of the circuit.

\section{Acknowledgements}

This work was supported in part by the Advanced Research Projects Agency-Energy, U.S. Department of Energy, under Award DE-AR0000216 and in part by the People Programme of the European Union's Seventh Framework Programme (FP7/2007-2013) under REA grant agreement $n^{\circ} 626117$.

\section{References}

Appelbaum, J., Bany, J., 1979 “Shadow effect of adjacent solar collectors in large scale systems," Solar Energy, vol. 23, pp. 497507.

Choi, B., 2015 "Differential Power Processing Submodule Integrated Converters for Photovoltaic Power Systems," Ph.D. Thesis, University of Colorado at Boulder.

Deline, C. Meydbray, J., Donovan, M., 2014 "Photovoltaic Shading Testbed for Module-Level Power Electronics: 2014 Update," NREL Report No. TP-5J00-62471. Golden, CO: National Renewable Energy Laboratory.

Deline, C., Sekulic B., Stein, J., Barkaszi, S., Yang, J., Kahn, S., 2014 "Evaluation of Maxim module-integrated electronics at the DOE regional test centers," 2014 IEEE 40 ${ }^{\text {th }}$ Photovoltaic Specialist Conference, pp. 986-991.

De Soto, W, Klein, S.A., Beckman, W.A., 2006 "Improvement and validation of a model for photovoltaic array performance," Solar Energy, vol. 80, no. 1, pp. 78-88.

Doubleday, K., Deline, C., Olalla, C., Maksimovic, D., 2015 "Performance of differential power-processing submodule DC-DC converters in recovering inter-row shading losses," $42^{\text {nd }}$ IEEE Photovoltaics Specialist Conference. 
Duffie, J.A., Beckman, W.A., 2006 Solar Engineering of Thermal Processes, $3^{\text {rd }}$ ed., Wiley New York, vol. 13.

Feldman, D., Barbose, G., Margolis, R., James, T., Weaver, S., Darghouth, N., Fu, R., Davidson, C., Booth, S., Wiser, R., 2014 "Photovoltaic System Pricing Trends: 2014 Edition," NREL technical report NREL/PR-6A20-62558.

Galtieri, J., Krein, P.T., 2015 “Impact of Differential Power Processing on Inter-Row Shading in Solar Arrays", $16^{\text {th }}$ IEEE Workshop on Control and Modeling for Power Electronics (COMPEL).

Jordan, D., Wohlgemuth, J., Kurtz, S., 2012 “Technology and climate trends in PV module degradation," $27^{\text {th }}$ European Photovoltaic Solar Energy Conference and Exhibition, PVSEC, Frankfurt, Germany.

Kesarwani, K., Stauth, J.T., 2012 "A comparative theoretical analysis of distributed ladder converters for sub-module PV energy optimization," in IEEE $13^{\text {th }}$ Workshop on Control and Modeling for Power Electronics (COMPEL),pp. 1-6.

Levron, Y., Clement, D., Choi, B., Olalla, C., Maksimovic, D., 2014 "Control of submodule integrated converters in the isolatedport differential power-processing photovoltaic architecture," IEEE Journal of Emerging and Selected Topics in Power Electronics, vol. 2, no. 4, pp. 821-832.

MacAlpine, S.M., Erickson, R.W., Brandemuehl, M.J., 2013 "Characterization of power optimizer potential to increase energy capture in photovoltaic systems operating under nonuniform conditions," IEEE Transactions on Power Electronics, vol. 28, no. 6, pp. 2936-2945.

Measurement and Instrumentation Data Center, ser. National Renewable Energy Laboratory, 2012, [Online]. Available http://www.nrel.gov/midc/.

Mejia, F.A., Kleissl, J., 2013 “Soiling losses for solar photovoltaic systems in California,” Solar Energy, vol. 95, pp. 357-363.

Olalla, C., Clement, D., Rodriguez, M., Maksimovic, D., 2013 “Architectures and control of submodule integrated DC-DC converters for photovoltaic applications," IEEE Transactions on Power Electronics, vol. 28, no. 6, pp. 2980-2997.

Olalla, C., Clement, D., Seok Choi, B., Maksimovic, D., 2013 “A branch and bound algorithm for high-granularity PV simulations with power limited subMICs," 2013 IEEE $14^{\text {th }}$ Workshop on Control and Modeling for Power Electronics (COMPEL).

Olalla, C., Deline, C., Maksimovic, D., 2014 "Performance of mismatched PV systems with submodule integrated converters," IEEE Journal of Photovoltaics, vol. 4, no. 1, pp. 396-404.

Olalla, C., Deline, C., Clement, D., Levron, Y., Rodriguez, M., Maksimovic, D., 2015 "Performance of power-limited differential power processing architectures in mismatched PV systems," IEEE Transactions on Power Electronics, vol. 30, no. 2, pp. 618631.

Passias, D., Kallback, B., 1984 “Shading effects in rows of solar cell panels," Solar Cells, vol. 11, no. 3, pp. 281-291.

Perez, R., Ineichen, P., Seals, R., Michalsky, J., Stewart, R., 1990 "Modeling daylight availability and irradiance components from direct and global irradiance," Solar Energy, vol. 44, pp. 271-289.

Pilawa-Podgurski, R.C.N., Perreault, D.J., 2013 "Submodule integrated distributed maximum power point tracking for solar photovoltaic applications," IEEE Transactions on Power Electronics, vol. 28, pp. 2957-2967.

Shenoy, P.S., Kim, K., Johnson, B.B., Krein, P.T., 2013 "Differential power processing for increased energy production and reliability of photovoltaic systems," IEEE Transactions on Power Electronics, vol. 28, pp. 2968-2979.

Shibin, Q., Cady, S.T, Dominguez-Garcia, A.D., Pilawa-Podgurski, R.C.N., 2013 "A distributed approach to MPPT for PV submodule differential power processing," in 2013 IEEE Energy Conversion Congress and Exposition (ECCE) pp. 2778-2785.

Solar Edge, 2015, Estimating Energy in PVWatts. [Online]. http://www.solaredge.com/files/pdfs/simulating solaredge _pv_watts_app_note.pdf.

van Schalkwijk, M., Kil, A.J., van der Weiden, T.C.J., 1997 "Dependence of diffuse light blocking on the ground cover ratio for stationary PV arrays," Solar Energy, vol. 61, no. 6, pp. 381-387. 